\title{
Programa de Innovación docente en la asignatura de Microbiología I
}

\section{Teaching Innovation Program in the subject of Microbiology I}

PATRICia Bernal Guzmán

https://orcid.org/0000-0002-6228-0496

Universidad de Sevilla

Departamento de Microbiología

pbguzman@us.es

DOI: http://dx.doi.org/10.12795/9788447231003.005

Pp.: 107-128 


\section{Descripción del contexto}

Este CIMA se ha impartido en la asignatura de Microbiología I en el grado de Biología. Microbiología I es una asignatura troncal de tercer año donde hay alrededor de 180-200 alumnos repartidos en tres clases. Este CIMA se ha impartido en el grupo C con un total de 69 alumnos y las clases han ocurrido en su totalidad en formato on-line a través de la plataforma de Enseñanza Virtual. Ha sido mi primera experiencia como docente de una asignatura de teoría.

\section{Diseño previo del CIMA}

\section{Mapa de contenidos y problemas claves}

El siguiente mapa de contenidos muestra los dos grandes problemas que vamos a tratar en este CIMA con una concepción neuronal en forma de red para representar no solo los contenidos sino las conexiones que existen entre ellas (García-Díaz, Porlán y Navarro, 2017). Antes de desarrollar el mapa de contenidos ha sido esencial una reflexión sobre los mimos con el objetivo de seleccionar solo los determinantes y trabajarlos de forma profunda (Bain, 2007). El primer problema se aborda con la pregunta de la figura 1 “pueden nuestras células producir compuestos de interés?" Esta pregunta nos va a llevar a indagar sobre los procesos metabólicos que ocurren en células procariotas ayudándonos de los contenidos estructurantes para conocer los pilares del problema y posteriormente iremos desarrollando los ejemplos más comunes e importantes a efectos prácticos. Este problema nos permite trabajar principalmente con conceptos y procedimientos intelectuales que nos permiten conocer todas las interacciones y relaciones existente entre los muchos conceptos que se trabajan en el problema 1. Como se puede ver en la figura 1, el metabolismo celular es un proceso circular, lo que queda

Ciclos de Mejora en el Aula (2020). Experiencias de Innovación Docente de la US Esta obra se distribuye con la licencia Creative Commons 
claramente reflejado en el centro del mapa, los elementos, la energía y las relaciones necesarias para mantener el ciclo componen las sub-preguntas para completar este mapa de contenidos. Hay dos conceptos secundarios: las inclusiones y las endosporas que, llegando a tener una relación con el metabolismo, son procesos excepcionales donde en lugar de metabolizar se produce un almacenamiento o una pausa en la actividad metabólica
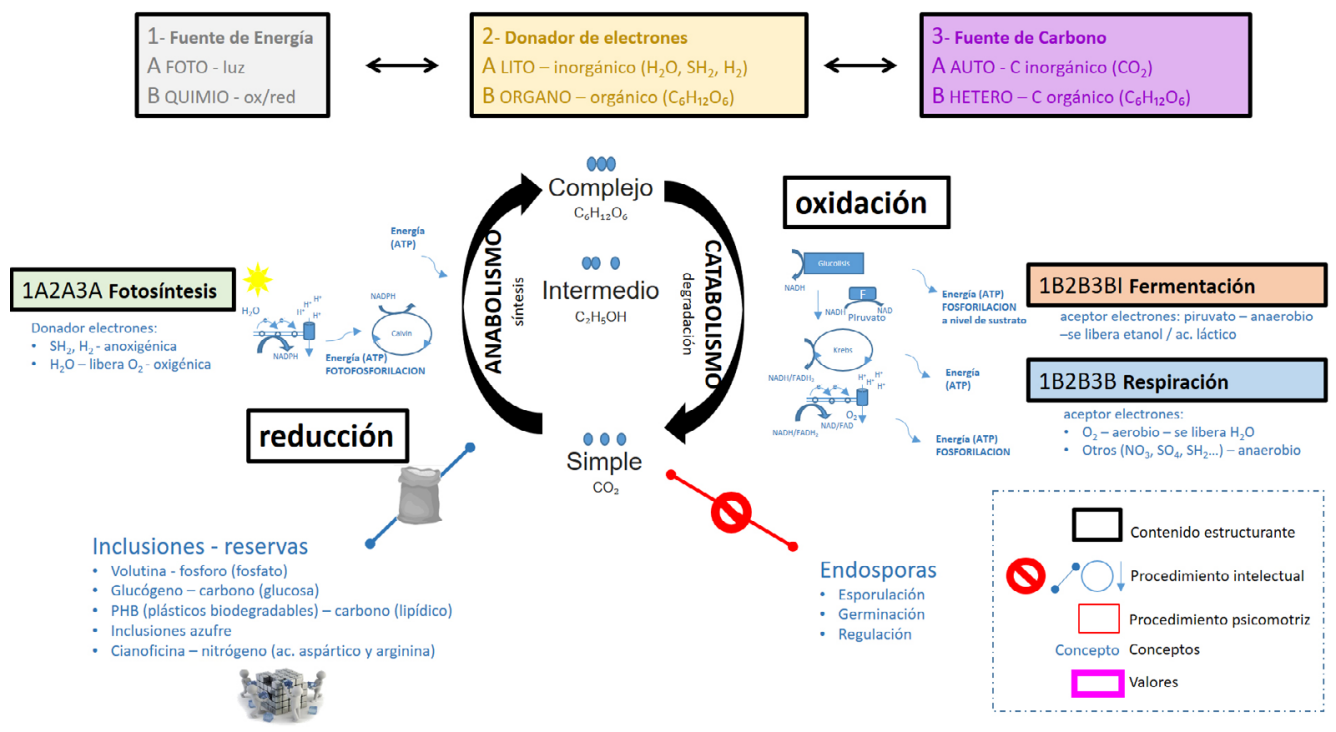

Figura 1. Problema 1: ¿Pueden las bacterias producir compuestos de interés?

El segundo problema representado en la figura 2, nos va a llevar a ocuparnos sobre el crecimiento bacteriano que difiere de forma importante al concepto de crecimiento en organismos superiores. Este problema nos permite trabajar con un mayor número de procedimientos psicomotrices (medidas, representaciones de datos, uso de instrumentos y el uso de variables como la presencia de oxígeno, la temperatura, la concentración de sal o el pH) y de valores (bioética), complementando la variedad de tipos de conocimientos operados en el primer problema.

Ciclos de Mejora en el Aula (2020). Experiencias de Innovación Docente de la US Esta obra se distribuye con la licencia Creative Commons 
Como cultivarlos $\longleftrightarrow$ aerobios psicrófilos ...
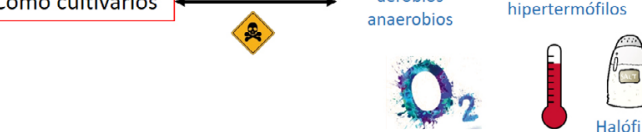

2
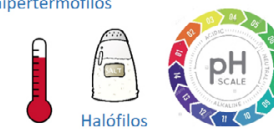

Alcalófilos / neutrófilos / acidófilos

Como podemos medirlo:

- Turbidez (DO)- Espectrofotómetro

- Recuento celular

- Microscopia - cámara recuento

- Placa - diluciones seriadas (ufc)

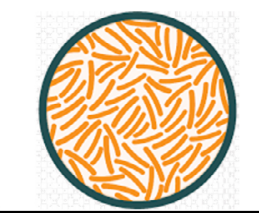

CRECIMIENTO bacteriano: aumento $\mathrm{n}$ ㅇ células

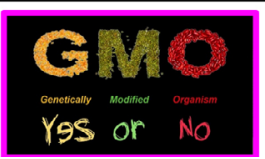

medios no renovados

Como podemos representarlo

- Curva crecimiento - fases

- Latencia

- Exponencial

- Estacionaria

- Muerte celular medios renovados (inmortalidad)

Instrumentos usados

- Quimiostato

- Turbidostato

en que se basan estas técnicas

Figura 2. Problema 2: ¿Se acabará nuestra fábrica? ¿Cómo crecen las bacterias?

\section{Modelo metodológico posible y secuencias de actividades}

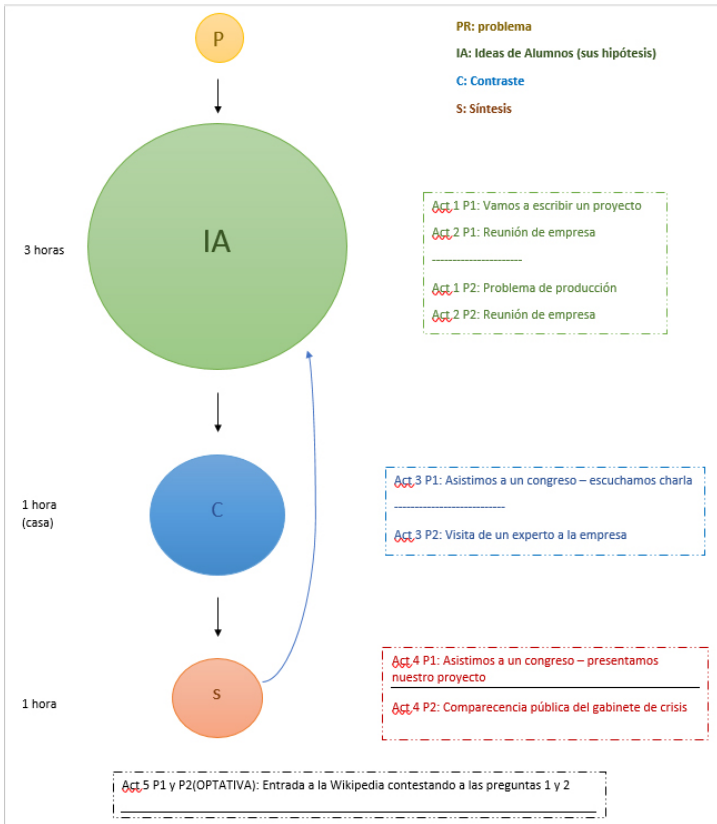

Figura 3. Modelo metodológico posible

Ciclos de Mejora en el Aula (2020). Experiencias de Innovación Docente de la US (c) $\odot$ Esta obra se distribuye con la licencia Creative Commons Reconocimiento-NoComercial-SinObraDerivada 
Mi modelo metodológico posible tienes las siguientes fases:1. Ideas de los alumnos; 2. Contraste y 3. Síntesis

Hay una primera parte llamada PR (problema) porque todo parte de un problema que tienen que resolver, de esta forma se comienza despertando el interés del alumnado (Finkel, 2008). Luego, en la primera fase, los alumnos tienen que crear sus hipótesis trabajando en pequeños equipos (4-5 personas), esto les permite reconfigurar el proceso de enseñanza-aprendizaje pasando de ser sujetos pasivos a ser sujetos activos que crean conocimiento dialogando y compartiendo opiniones con sus compañeros (Finkel, 2008). Las preguntas que van a intentar contestar en grupo son las mismas que el día antes han respondido de manera individual en el cuestionario inicial con algunas matizaciones. Posteriormente, hay una puesta en común entre todos los alumnos donde comparten las hipótesis con el resto de compañeros. Mi papel es el de moderadora, escribiendo en la pizarra las ideas principales que van saliendo. En la fase de contraste, los alumnos tienen que enfrentarse a los postulados actuales sobre el tema anterior y comparar sus ideas e hipótesis con el conocimiento más actualizado del tema. En la fase 3, los alumnos llevan a cabo una actividad de sintesis donde destacan las ideas principales.

A continuación, se presentan las secuencias de actividades que comienzan con una introducción donde se explica el funcionamiento del CIMA2. En la clase anterior se pasó un cuestionario con una secuencia de preguntas para que los alumnos se enfrentarán a los problemas 1 y 2 descritos en el mapa de contenidos de forma individual. Los alumnos tuvieron 30 min para reflexionar sobre las preguntas y plasmar la concepción que tenían de los problemas antes de empezar a trabajar con ellos en el CIMA.

Ciclos de Mejora en el Aula (2020). Experiencias de Innovación Docente de la US Esta obra se distribuye con la licencia Creative Commons 
Tabla 1. Problema 1: ¿Pueden las bacterias producir compuestos de interés?

\section{Martes 10 noviembre}

\begin{tabular}{|l|l|l|}
\hline $\begin{array}{l}\text { Actividad 1: Juego de Rol 1 - Somos biotecnólogos y } \\
\text { vamos a montar una empresa. }\end{array}$ & Fase 1 & 50 min \\
\hline
\end{tabular}

Les propongo un juego de rol en el que queremos montar una empresa de biotecnología (20BACl) y queremos producir un compuesto de valor añadido usando bacterias. Vivimos en Sevilla en 2020. Les muestro una foto o video de la que será nuestra empresa. Les explico que la US nos cederá las instalaciones y nos financiará durante el primer año si entreguemos un proyecto donde demostremos que nuestra idea es factible.

La empresa va a estar formada por 4 plantas de producción y en cada planta habrá 3 grupos de trabajo (grupos preformados por ellos mismos para otra actividad de la asignatura). Para escribir el proyecto, cada grupo va a escribir la parte de su planta de producción. Estas preguntas son las mismas que el día anterior han tenido que responder en el formulario de forma individual y en esta actividad los estudiantes ponen en común sus respuestas individuales a las preguntas del cuestionario, tratando de construir respuestas colectivas. Luego tendremos una reunión donde pondremos todas las respuestas colectivas en común para redactar un único proyecto que cubra las 3 plantas de producción.

Los grupos de cada planta están conformados por: un jefe de grupo, un investigador postdoctoral, un investigador predoctoral, un estudiante de master, un técnico de laboratorio (estos papeles son repartidos por orden alfabético del nombre empezando por el final).

A los grupos 1, 2 y 3 se les asignan unas instalaciones para crecer cianobacterias (Spirulina) y cuentan con luz y un gran tanque de CO2, esta planta de producción quiere vender espirulina a la hostelería sevillana.

Los grupos 4, 5 y 6 cuentan con instalaciones para crecer Lactobacillus delbrueckii en grandes fermentadores e inmensas cubas de leche, el objetivo de esta planta es producir yogurt sevillano de una calidad excepcional a un precio competitivo.

Los grupos 7, 8 y 9 cuentan con instalaciones anaeróbicas para crecer Geobacter y su objetivo es descontaminar aguas y suelos de la ribera del Guadalquivir con altas concentraciones de metales. Por último, los grupos 10, 11, 12 y 13 cuentan con instalaciones para crecer Pseudomonas putida en condiciones aeróbicas. P. putida es una cepa de biocontrol y PGPR que puede proteger a las plantas del ataque de fitopatógenos y promover el crecimiento vegetal. Esta planta de producción proporcionará P. putida a los agricultores locales para mejorar el rendimiento de sus cultivos.

Ciclos de Mejora en el Aula (2020). Experiencias de Innovación Docente de la US Esta obra se distribuye con la licencia Creative Commons Reconocimiento-NoComercial-SinObraDerivada Internacional (CC BY-NC-ND 4.0.) 
La US nos pide que demostremos en el proyecto que nuestras bacterias pueden producir/degradar los compuestos de interés que describimos en nuestro proyecto.

Para facilitar el trabajo a la persona encargada de poner toda la información del proyecto en un solo documento vamos a contestar una serie de preguntas más específicas que nos servirán para contestar la gran pregunta (cada grupo contestará sobre su proyecto específico):

1. ¿Sabéis si vuestra bacteria puede transformar unos compuestos en otros? ¿Creéis que pueden sintetizar o degradar compuestos? Razona como ocurriría todo esto

2. ¿De dónde creéis que viene la energía y los sustratos iniciales para llevar a cabo estas transformaciones? Pensad en las condiciones de vuestra planta de producción ¿Sabrías nombrar los trofismos (estados nutricionales) que se dan en vuestra bacteria? ¿Sabéis cómo relacionar estos procesos con la oxidación y la reducción?

3. Hay tres procesos metabólicos principales, ¿Cuál crees que es el principal que se va a dar en vuestra bacteria con las condiciones señaladas? si este fueran una gran caja negra, ¿podríais indicar que entra en la caja y que sale sin dar detalles de lo que pasa en las fases intermedias?

4. ¿Podríais abrir las cajas negras y describir que pasa dentro? ¿Dónde ocurren estas reacciones?

5. ¿Qué ocurre cuando hay exceso de algún componente? ¿Sabéis si vuestra bacteria puede pasar a un estado "no metabolico" sin morir?

La discusión se lleva a cabo en clase, en grupos creados dentro de la aplicación BlackBoard (lo haré de forma manual). Iré pasando por los grupos cuando me llamen en el chat.

El material de discusión tiene que ser entregado por correo electrónico antes de la siguiente clase (miércoles) de forma provisional (para tener material sobre el que trabajar para la clase siguiente) y antes del lunes siguiente de forma definitiva. Lo leo y les hago algunos comentarios para dirigirlos a la discusión de la siguiente clase. El correo va dirigido a todos los miembros del grupo, les agradezco el trabajo y les hago comentarios positivos, luego los animo a profundizar en ideas que han dejado muy generales o les hago preguntas que no se han hecho para que sigan buscando información y pensando sobre el tema.

Recursos: Fotografías y/o video de la empresa biotecnológica donde vamos a trabajar. Imagen de Word con los diferentes grupos y su descripción. 13 grupos ya preformados, tengo la información de los Grupos con nombres y correos electrónicos y su papel en el grupo de investigación. Listado de preguntas que tienen que salir en la puesta en común para ir dirigiendo - preparación de temario para asegurarme que no se queda nada atrás y diapositivas por si hay que ilustrar algo. Imprimir los trabajos entregados para introducir y discutir ideas no totalmente acertadas

Ciclos de Mejora en el Aula (2020). Experiencias de Innovación Docente de la US Esta obra se distribuye con la licencia Creative Commons Reconocimiento-NoComercial-SinObraDerivada Internacional (CC BY-NC-ND 4.0.) 
Tabla 2. Problema 1: ¿Pueden las bacterias producir compuestos de interés? Actividad 2

\title{
Miércoles 11 y lunes 16 noviembre
}

\begin{abstract}
Actividad 2: Juego de Rol 2 - Tenemos una
reunión de empresa para poner nuestro proyecto en pie

Después de trabajar en grupos, tenemos que poner nuestra información en común para poder escribir el proyecto final. Cada jefe de grupo tiene 5 min para contar todo lo que han averiguado de su bacteria y como podría llevar a cabo la actividad propuesta para esa planta de producción.

Yo actúo de moderadora y apoyo dibujando las ideas principales en la pizarra blanca. Con esta discusión vamos a ir construyendo conocimiento a partir de sus trabajos. Después de las exposiciones de cada planta de producción, los otros grupos pueden hacer preguntas. Yo tengo una lista de las ideas que tienen que ser discutidas e iré orientado la discusión.
\end{abstract}

Recursos: pizarra blanca, también pueden compartir pantalla. Yo tengo un pdf con ilustraciones para visualizar conceptos difíciles de entender de manera puntual. Tengo el material que me han entregado los alumnos y la lista de preguntas que tienen que ser discutidas

\section{Tabla 3. Problema 1: ¿Pueden las bacterias producir compuestos de interés? Actividad 3}

\begin{tabular}{|c|c|c|}
\hline & & \\
\hline \multicolumn{3}{|l|}{$\begin{array}{l}\text { Al final de la reunión de empresa, nos inforn } \\
\text { pongo una foto para que vean en que cons } \\
\text { nuestro campo de trabajo van a exponer y as } \\
\text { últimos descubrimientos en nuestro campo. } \\
\text { nuestra producción y solucionar problemas } \\
\text { video sobre lo que cada uno está trabajand } \\
\text { También nos dicen que nuestros proyecto } \\
\text { presentados en el congreso y que un represe } \\
\text { para conocer nuestra propuesta y ver su via } \\
\text { proyecto a presentar). Para el día siguiente, } \\
\text { los otros grupos de su misma planta de pro } \\
\text { "por capas". Cada grupo va a presentar una } \\
\text { de la capa anterior. Esto lo sabrán con tie } \\
\text { organizarse. } \\
\text { Les explico que en la clase siguiente so }\end{array}$} \\
\hline
\end{tabular}

Ciclos de Mejora en el Aula (2020). Experiencias de Innovación Docente de la US Esta obra se distribuye con la licencia Creative Commons Reconocimiento-NoComercial-SinObraDerivada Internacional (CC BY-NC-ND 4.0.) 
Recursos: Links subidos a EV con la charla que van a atender en el congreso. Fotografía para ambientarnos en el congreso y del premio a la primera pregunta. Las 4 presentaciones hechas por ell@s se subirán a EV y si así lo desean a Youtube.

\section{Tabla 4. Problema 1: ¿Pueden las bacterias producir compuestos de interés? Actividad 4}

\section{Martes 17 noviembre}

\begin{tabular}{|l|l|l|}
\hline $\begin{array}{l}\text { Actividad 4: Juego de Rol - Asistimos } \\
\text { a un congreso - presentamos } \\
\text { nuestro trabajo }\end{array}$ & 50 min \\
\hline $\begin{array}{l}\text { Hoy seguimos en el congreso y toca presentar los } 4 \text { proyectos de cada } \\
\text { planta de producción. Tiene que presentar alguien del grupo que no haya } \\
\text { participado con anterioridad. Cada proyecto tiene } 5 \text { minutos y luego tenemos } \\
10 \text { min de preguntas. El/la que pregunte primero se lleva un peluche de su } \\
\text { bacteria (foto para que lo vean). Fase de sintesis donde los alumnos tienen } \\
\text { que resumir las ideas principales y presentarlas. En esta fase van a quedar } \\
\text { reflejados todos los acuerdos y desacuerdos, con los diferentes argumentos } \\
\text { que los sustentan. } \\
\text { Al final de la clase les comentó que la US ha decidido financiar nuestro } \\
\text { proyecto y podemos montar nuestra empresa de biotecnología. }\end{array}$ \\
\hline
\end{tabular}

Recursos: Fotografía para ambientarnos en el congreso y del premio a la primera pregunta. Las 4 presentaciones se subirán a EV y si así lo desean a Youtube. Algún video o fotos para celebrar la buena noticia de la subvención.

\section{Tabla 5. Problema 2: ¿Se acabará nuestra fábrica? ¿Cómo crecen las bacterias? Actividades 1-5}

\begin{tabular}{|l|l|l|}
\hline $\begin{array}{l}\text { Actividad 1: Juego de Rol - Tenemos un problema de } \\
\text { producción }\end{array}$ & Fase 1 & 50 min \\
\hline Estamos en los primeros meses de nuestra empresa y nos enfrentamos a \\
nuestro primer problema importante: la producción está parada porque \\
nuestros cultivos tienen problemas para crecer. Tenemos que identificar que \\
está pasando y para ello tenemos que contestar a las siguientes preguntas \\
que nos van a ayudar a identificar el problema en cada caso. \\
- Lo primero es entender cómo crecen las bacterias. ¿Sabéis que tiene que \\
ocurrir para que una célula pueda duplicarse? ¿Cómo estáis midiendo el \\
crecimiento? ¿podéis representarlo para mostrar el problema?
\end{tabular}

Ciclos de Mejora en el Aula (2020). Experiencias de Innovación Docente de la US Esta obra se distribuye con la licencia Creative Commons 
- De los 4 factores principales que tienen mayor influencia en el crecimiento bacteriano, estos son los que están afectando a vuestras plantas de producción, ¿por qué estas condiciones inhiben el crecimiento de vuestras bacterias? ¿Cómo podríamos solucionarlo? ¿Usaríais organismos modificados genéticamente?

- Cianobacterias - pH ácido

- Lactobacillus - altas concentraciones de sal - contaminación con Salinibacter ruber

- Geobacter - altas concentraciones de oxígeno

- Pseudomonas putida - temperatura (42으) en el tanque

Recursos: similares a la actividad 1 del problema 1

Actividad 2: Reunión de empresa para solucionar el problema

\begin{tabular}{|l|l}
\hline Fase 1 & $\begin{array}{l}100 \\
\text { min }\end{array}$ \\
\hline
\end{tabular}

Similar a la actividad 2 del problema 1. Iré introduciendo más preguntas si los alumnos no llegan a la profundidad suficiente

Recursos: similar a la actividad 2 del problema 1

Actividad 3: Visita de un experto de otra empresa

Fase 2

$60 \mathrm{~min}$

Esta visita será "virtual" y consistirá en ver un video de Youtube en casa sobre el tema en cuestión. Esta será la actividad de contraste. También se va a formar un gabinete de crisis (intercambiar información con los otros grupos de la misma planta de producción) y al día siguiente el comité de expertos del gabinete de crisis dará una comparecencia explicando los problemas y como se van a solucionar (esto lo sabrán con tiempo para que puedan prepararse).

Recursos: similar a la actividad 3

\begin{tabular}{|l|l|l|}
\hline Actividad 4: Reunión del Comité de crisis & Fase 3 & 50 min \\
\hline
\end{tabular}

El comité de crisis da una comparecencia pública para explicar los problemas y sus soluciones. 5 min cada planta y 10 min preguntas. Tienen que participar alumnos que no lo hayan hecho todavía. Fase de síntesis donde los alumnos tienen que resumir las ideas principales y presentarlas.

Recursos: similar a la actividad 4 del problema 1

\begin{tabular}{|l|l|l} 
Actividad 5: Entrada a la Wikipedia - OPTATIVA & Fase 3 & casa
\end{tabular}

Les propongo que conviertan el material que han desarrollado en una entrada para la Wikipedia. Sería subir el proyecto aprobado por la US. Cada grupo entregaría el suyo y yo lo fusionaría para convertirlo en un solo artículo. Si hay grupos suficientes se puede elegir entre la pregunta del metabolismo y la pregunta del crecimiento y hacer dos entradas. Cada grupo elegiría solo una de las dos.

Recursos: instrucciones para el envío de material (texto y figuras).

Ciclos de Mejora en el Aula (2020). Experiencias de Innovación Docente de la US Esta obra se distribuye con la licencia Creative Commons 


\section{Cuestionario inicial-final}

Como indicamos anteriormente, los alumnos se han enfrentado a una serie de preguntas para afrontar los problemas planteados en el mapa de contenidos de forma individual antes de comenzar el CIMA, esta serie de preguntas se conocen como cuestionario inicial. Una vez desarrollando el CIMA, los alumnos vuelven a enfrentarse a las mismas preguntas (cuestionario final) de forma individual, lo que nos va a permitir evaluar el desarrollo del CIMA. En esta ocasión, los cuestionarios se han desarrollado de forma anónima, pero con marcas que me han permitido identificar los cuestionarios del mismo alumno antes y después. A continuación, se puede leer el cuestionario que incluye una breve descripción del contexto donde se va a desarrollar el problema:

"Somos un grupo de microbiólogos que queremos montar una empresa para producir compuestos de valor añadido usando bacterias. La Universidad de Sevilla tiene un programa de ayuda para este tipo de empresas basadas en la biotecnología. Con la ayuda nos proporcionan los laboratorios para comenzar y nos ayuda con la financiación, pero tenemos que entregar un proyecto detallado de la parte técnica para demostrar que nuestra empresa puede tener éxito. Para ello lo primero que tenemos que saber es la capacidad que tienen las bacterias para transformar unos productos en otros y que ocurre a nivel energético. ¿Puedes ayudarme a rellenar el cuestionario de la US para solicitar la ayuda que nos permitirá comenzar nuestra empresa?

1. ¿Sabes si las células pueden transformar unos compuestos en otros? ¿Crees que pueden sintetizar o degradar compuestos? Razona como ocurriría todo esto

2. ¿De dónde crees que viene la energía y los sustratos iniciales para llevar a cabo estas transformaciones? ¿Sabrias nombrar los trofismos (estados

Ciclos de Mejora en el Aula (2020). Experiencias de Innovación Docente de la US Esta obra se distribuye con la licencia Creative Commons 
nutricionales) según el origen de la energía y los sustratos iniciales? ¿Se te ocurre cómo relacionar estos procesos con la oxidación y la reducción?

3. Hay tres procesos metabólicos principales, ¿sabrías ponerles nombres? si estos fueran una gran caja negra, ¿podrías indicar que entra en la caja y que sale sin dar detalles de lo que pasa en las fases intermedias?

4. ¿Podrías abrir las cajas negras y describir que pasa dentro? ¿Sabes dónde ocurren estas reacciones?

5. ¿Qué crees que hace la célula cuando hay exceso de algún componente? ¿Conoces algún caso de célula sin metabolismo? ¿estaría viva? ¿Podrías describirla?

6. Para saber si nuestra fabrica se agotará necesitamos saber cómo crecen las bacterias. ¿Qué crees que tiene que ocurrir para que una célula pueda duplicarse? ¿Sabrías medir el crecimiento? ¿y representarlo?

7. Si somos capaces de mejorar el crecimiento bacteriano podremos aumentar nuestra producción, ¿sabrías nombrar los 4 factores principales que tienen mayor influencia en el crecimiento bacteriano?

\section{Aplicación del CIMA}

\section{Relato resumido de las sesiones}

A continuación, se describe el diario de las sesiones.

Martes 10 de Nov. Los alumnos se notaban entusiasmados y empezaron a trabajar en grupo de forma ordenada y sin complicaciones (ya sabían que hacer porque lo habíamos hecho en el CIMA 1). Cuando terminó la clase tuve que avisarles que era la hora, lo que me dio a entender que estaban muy implicados en el trabajo en grupo

Ciclos de Mejora en el Aula (2020). Experiencias de Innovación Docente de la US Esta obra se distribuye con la licencia Creative Commons 
Miércoles 11 Nov. La actividad era la de poner en común el trabajo en grupo, pero no conseguí que me hablaran, la única forma de sacar información fue yo hablando y ellos contestando por el chat. No era lo que tenía planeado y me sentí muy frustrada. La clase que viene tenemos la misma actividad y voy con temor porque no sé qué cambiar para que hablen, estoy frustrada.

Lunes 16 Nov. La clase de hoy era también en principio de ellos hablando, pero dada la experiencia del miércoles, lo adapte a lo que ocurrió ese día. Primero hice un miniresumen de lo que habíamos visto hasta ese momento y luego usando la pizarra blanca hablamos de los dos temas que nos faltaban inclusiones y esporas. Durante el apartado de las inclusiones fueron bastante participativos, con la espora costó más porque sabían menos y era menos intuitivo. Pero el sentimiento fue más positivo que el miércoles, seguramente porque yo no esperaba tanto como el miércoles y mis expectativas y la realidad estuvieron más cerca. Dejarlos escribir en la pizarra en lugar de hablar por el micro les resulta mucho más cómodo a ellos y me permite llevar a cabo el objetivo de la clase. Yo voy organizando las ideas que van saliendo en la pizarra y sigo haciendo preguntas para que sigan profundizando en el aprendizaje. Durante el fin de semana me llegaron los informes de lo que habían discutido en grupo y ya se podía apreciar cómo habían ido evolucionando desde el primer cuestionario individual que les pasé.

Martes 17 Nov. Hoy empezó el congreso y dos grupos (de 4) habían preparado charlas. En principio las charlas eran de 5 minutos, pero las 2 fueron de unos 15 min. Hubo una pregunta de una alumna que siempre es muy activa y se llevó el peluche (un peluche de una bacteria que había prometido a quien hiciera la primera pregunta del congreso con cámara y micrófono). Pusieron cámaras y micro e hicieron muy buenas presentaciones. Yo introduje algunas preguntas que contestaron entre el chat y los ponentes con aclaraciones mías. Ha sido un buen día y los dos grupos que no tenían las charlas preparadas para hoy me 
pidieron presentar mañana, así que mañana sigue el congreso y la clase de mañana que era de puesta en común la presentaré, pero tendrán que trabajarlo en casa. Muy buenas sensaciones hoy. Tuvimos a Esperanza de invitada para las observaciones cruzadas.

Miércoles 18 Nov. Los otros dos grupos hicieron sus presentaciones, hicieron un trabajo fantástico y fueron aplaudidos y vitoreados por sus compañeros. En los últimos 10 minutos les presenté la siguiente actividad que en lugar de hacerlo en clase la tienen que hacer por su cuenta y entregármelo antes del domingo. Mi sensación fue muy buena, la única pega es que el número de alumnos fue más bajo de lo habitual pero mis compañeros me han dicho que les pasa lo mismo, porque los temas que estamos viendo ya no entran en el examen del primer parcial que tienen el día 30 de noviembre.

Lunes 23 Nov. La mayoría de los grupos me ha enviado el formulario antes de la clase de hoy, me ha dado tiempo de leerlos, pero no de contestarles porque me los enviaron el domingo tarde e incluso el lunes por la mañana antes de la clase.

Hemos puesto en común los temas de crecimiento y como medirla, han sido muy participativos y he salido contenta - ellos van siguiendo, escriben en la pizarra y preguntan por el chat

Al final de la clase les propuse que pensaran sobre una pregunta desde el punto de vista bioético, se quedaron sorprendidos, creo que ha sido la primera vez que alguien les plantea este tipo de preguntas. ¿Usaríais Organismos Modificados Genéticamente en vuestras fabricas para optimizar/mejorar/abaratar los procesos?

Martes 24 Nov. Hoy me ha costado más que participaran, sobre todo al principio, creo que era porque no sabían por dónde comenzar. Cuando he empezado yo, ellos han sabido seguir y se ha animado la clase.

He hecho la pregunta de bioética y ha habido un poco de debate -un alumno ha encendido el micro para defender su postura de no a los OMG - (casi todos SI/ 4 NO) pero

Ciclos de Mejora en el Aula (2020). Experiencias de Innovación Docente de la US Esta obra se distribuye con la licencia Creative Commons 
se nos ha acabado el tiempo, una pena porque pintaba muy bien para haber trabajado con ellos. Al final les he pedido una lectura para mañana.

La clase de mañana la he tenido que cambiar porque no había metido en mi CIMA2 la $1 / 2$ hora de responder el cuestionario de nuevo. Les he pedido hoy que hagan una lectura en casa (les he colgado la lectura en EV).

Miércoles 25 Nov. Hoy es el último día que les doy “teoría", con el CIMA2 también termina para mí la impartición de docencia en la asignatura. El lunes tienen un examen de parte de la asignatura (primer parcial) y luego estaré 5 horas más con ellos, pero serán ellos los que impartirán seminarios sobre parte del temario de la asignatura. El número de alumnos hoy ha vuelto a subir ligeramente. Tenían que hacer una lectura entre la clase de ayer y la de hoy, pero pregunté y solo una persona lo había leído así que les di tiempo para leer en clase y luego hicimos una puesta en común, esto duró media clase, la otra media estuvieron haciendo el cuestionario, pero me dijeron que no lo habían terminado (ha habido pocos alumnos que luego lo hayan entregado). Al final de clase hice una encuesta preguntado si se habían divertido mientras aprendían Microbiología y solo una persona contestó que no. Hubo bastantes preguntas por chat y algunas micro sobre temas que entran en el examen del lunes y se contestaban entre ellos. Sensaciones buenas en general. Sabor agridulce por acabar y con ganas de seguir experimentando. Tuvimos a Belén de invitada para las observaciones cruzadas.

\section{Evaluación del aprendizaje de los estudiantes}

En este apartado se presentan las escaleras de aprendizaje de los alumnos que nos permite evaluar la evolución de la clase durante el CIMA con respecto a cada una de las preguntas formuladas en el cuestionario inicial y final. Se incluyen un total de 6 escaleras (Fig. 4) en las que podemos ver distintos estados, tanto en los niveles de partidas, como en las evoluciones y los niveles finales alcanzados. Así, por ejemplo, en todas las escaleras excepto la de trofismo (en rojo), más del $50 \%$ de los alumnos parte 
del nivel basal. Sin embargo, la forma en la que los alumnos suben estas escaleras es bastante diversa y mientras en la escalera de metabolismo (en negra) la mayoría es capaz de subir de 3 a 4 escalones o la escalera de endospora (verde) con una subida generalizada de 2-3 escalones, otras escaleras muestran mucha más dispersión y la subida no es ni tan general ni tan acusada (escaleras de crecimiento, en amarillo y morado). En algunos casos, como la escalera de reserva (en azul), hay un altísimo porcentaje que se queda en el escalón inicial sin avanzar, indicando
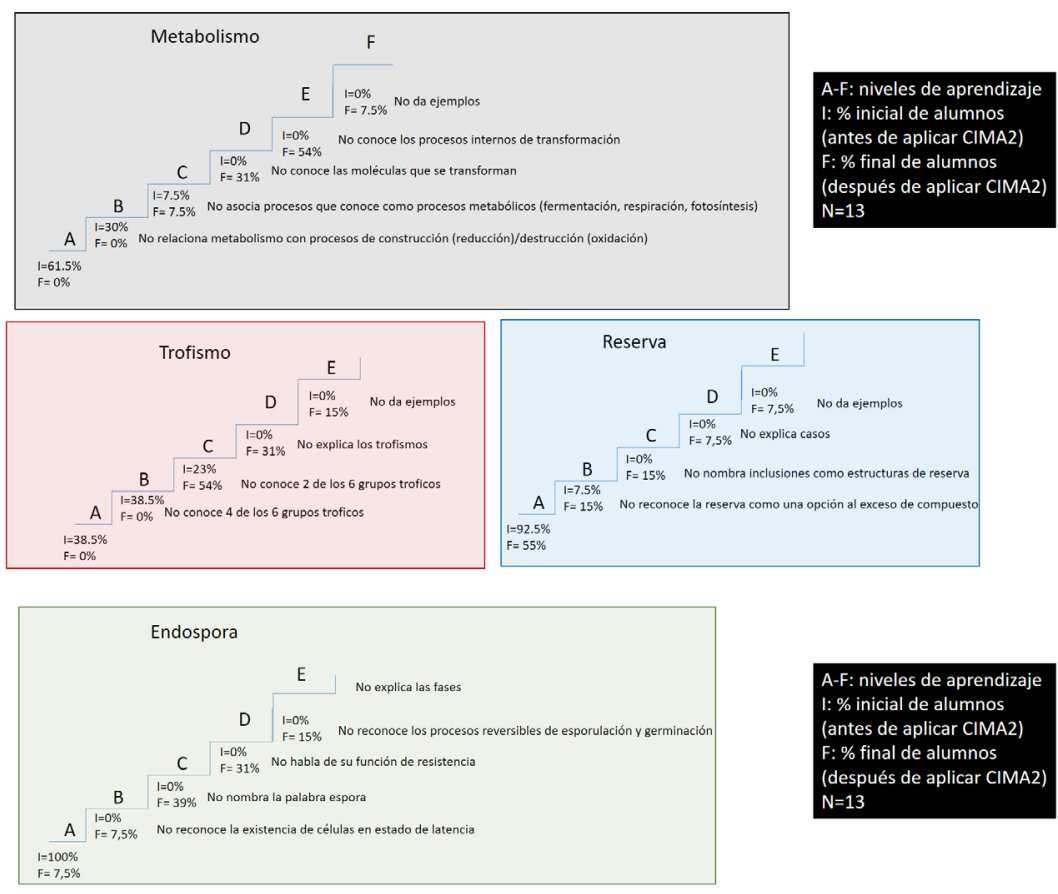

A-F: niveles de aprendizaje I: \% inicial de alumnos

(antes de aplicar CIMA2) F: \% final de alumnos

(después de aplicar CIMA2)

$\mathrm{N}=13$

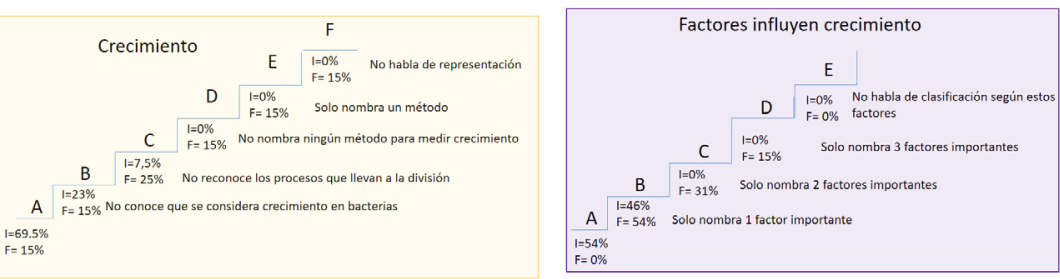

Figura 4. Escaleras de aprendizaje para las principales preguntas trabajadas en el CIMA

Ciclos de Mejora en el Aula (2020). Experiencias de Innovación Docente de la US (c) Esta obra se distribuye con la licencia Creative Commons Reconocimiento-NoComercial-SinObraDerivada Internacional (CC BY-NC-ND 4.0.) 
claramente que la forma en la que se ha abordado el problema es insatisfactoria y no ha permitido a los alumnos evolucionar. Hay una correlación entre el tiempo y las actividades dedicadas a cada problema y la evolución de las escaleras de aprendizaje. Aquellos problemas que se han considerado estructurantes y que, por tanto, tenían una mayor dedicación en las actividades a desarrollar, han resultado ser los más exitosos cuando se han analizado las escaleras, poniendo como ejemplo principal el metabolismo celular (escalera en negro). En el caso de la escalera con menor evolución positiva, además de destacar el menor tiempo dedicado a este problema por no ser estructurante, también se puede plantear si la pregunta del cuestionario estaba formulada de forma correcta, puede que haya sido demasiado general y que los estudiantes no hayan sabido exactamente lo que se estaba preguntado. De forma general, se puede decir que la evaluación de la clase ha sido muy positiva y en todos los casos (aunque con diferentes grados) vemos evolución y mejora, es decir, subida de la escalera.

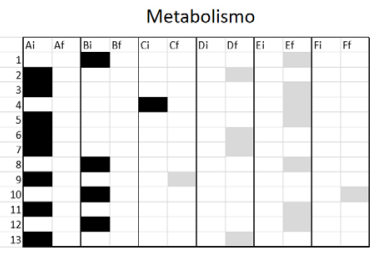

Endospora

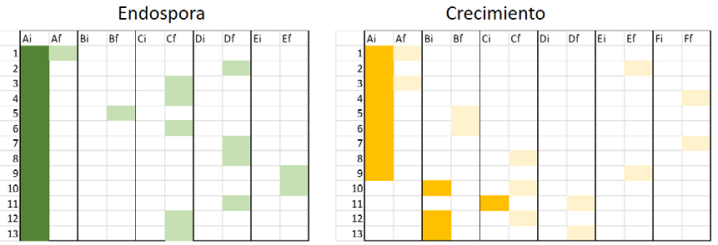

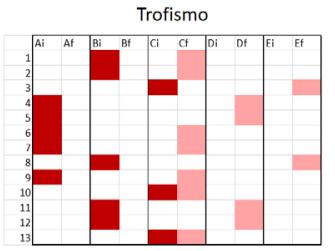

Crecimiento

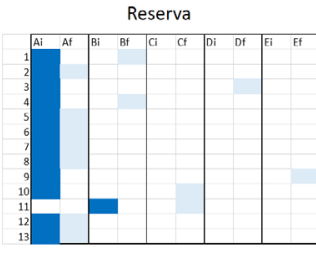

Factores influyen crecimiento

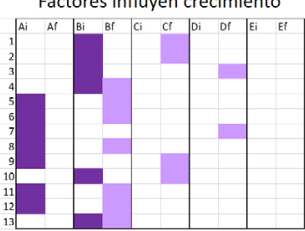

A-F: niveles de aprendizaje - 6 grandes problemas (negro, rojo, azul, verde, amarillo y morado) i: inicial (antes de aplicar CIMA2) color oscuro / f: final (después de aplicar CIMA2) color claro $\mathrm{N}=13$ alumnos

Figura 5. Cuadros de evolución de cada pregunta/escalera por alumnos

En los cuadros de evolución podemos ver el progreso individual de cada alumno, mostrando de forma clara como la evolución de los mismos no es uniforme cuando se comparan las preguntas, es decir el alumno X no evoluciona de 
igual forma en la pregunta 1, 2, 3, 4, 5 y 6. Por tanto, la evolución que vemos en las escaleras tiene dos grandes variables, la pregunta y el alumnado. Pongamos como ejemplo el alumno 9, con una evolución muy restringida en las escaleras de metabolismo y trofismo (2 escalones), mientras sus compañeros subieron entre 3 y 4 escalones en las mismas escaleras (Fig. 5). Este mismo alumno, muestra una evolución amplísima en las escaleras de la endospora, y reserva, donde fue uno de los pocos alumnos que consiguió llegar a la cima. Esto es especialmente interesante porque la evolución de la clase en la escalera de reserva fue realmente baja (una inmensa mayoría no sube ningún escalón), pero el alumno 9 consiguió llegar hasta el final de la misma. Resulta de especial interés el hecho de que los contenidos de estas dos escaleras (reserva y endospora) se trabajaron en el mismo día, por lo que una hipótesis de trabajo es que estemos ante un alumno con un alto nivel de comprensión y que asistiera a clase ese día, pero no lo hiciera los días que no consiguió avanzar en las escaleras de metabolismo y trofismo (también coincidieron en el tiempo), pero sí lo hicieron la mayoría de sus compañeros, que por otro lado no avanzaron en la escalera de reserva.

\section{Evaluación del CIMA}

\section{Cuestiones a mantener y cambios a introducir para un futuro Ciclo de Mejora}

La evaluación del CIMA tiene muchas facetas y a la hora de evaluar el aprendizaje de los estudiantes ha sido clave mantener un ambiente de igualdad y respeto para que los alumnos se sientan libren para expresarse sin ser juzgados, lo que va a permitir un aprendizaje mejor y más profundo (Rivero y Porlán, 2017). La experiencia del CIMA ha sido positiva en términos generales, aunque con

Ciclos de Mejora en el Aula (2020). Experiencias de Innovación Docente de la US Esta obra se distribuye con la licencia Creative Commons 
mucho margen para la mejora en todos los aspectos como ha quedado patente al analizar las escaleras de aprendizaje y la tabla de evolución de los estudiantes. El entorno creado para resolver problemas que pudieran ser de su interés fue bueno y los atraía, pero luego la realidad era de unos contenidos mucho más de ciencia básica y no aplicada y puede que algunos hayan perdido interés. Esto es algo que supone un reto a la hora de ser mejorado, porque se necesitaría más tiempo para poder hacer la parte básica y luego pasar a la aplicada. La participación no ha sido mala, pero creo que podría mejorar cuando las clases vuelvan a ser presenciales. No puedo comparar con otros años porque esta ha sido mi primera experiencia como docente de una asignatura teórica. Algunas actividades como ir de congreso, ganarán mucho cuando podamos hacerlo presencialmente, porque podremos recrear el ambiente de un congreso y sumergirnos mejor en el contexto usado para resolver nuestros problemas. En las sesiones que poníamos en común los problemas que habían discutido entre ellos me daba cuenta de que su bagaje intelectual era muy diferente al mío y que los conocimientos que tenían de otras asignaturas que habían estudiado recientemente influía grandemente en nuestro trabajo, por ser conocimientos parecidos (incluso paralelos), pero no idénticos (por ejemplo, mismos procesos que han estudiado en Bioquímica o Genética en células eucariotas, ahora los vemos en células procariotas). Destacarles las diferencias e insistir durante las discusiones en estos puntos es algo a incluir en mis próximos CIMAS para que al final de la asignatura todos tengan claro los grandes pilares de la Micro por ejemplo que la respiración en bacterias no se da en las mitocondrias ni la fotosíntesis en los cloroplastos porque las bacterias no tienen estos orgánulos y que en realidad estos orgánulos son bacterias que por endosimbiosis dieron lugar a los organismos eucariotas. Creo que es un problema general de la carrera de Biología que es muy amplia y hay muchos conocimientos parecidos, pero no idénticos.

Ciclos de Mejora en el Aula (2020). Experiencias de Innovación Docente de la US Esta obra se distribuye con la licencia Creative Commons 
Creo que es importante destacar y aclarar muy bien las diferencias que hacen únicos y que distinguen a los organismos vivos para que estructuren sus cabezas "como biólogos".

Mi sensación es que ahora conozco mucho más a mis alumnos y ellos a mí y estoy en mejor posición para ayudarles y ellos de pedir lo que necesitan, pero ya casi ha acabado nuestro trabajo juntos, lo que me apena mucho.

Algo que este curso ha cambiado para siempre en mi cabeza es la percepción de los roles que tenemos cada uno en la enseñanza (docentes y alumnos). Ahora veo con claridad y sin ninguna duda que los alumnos son lo más importante y tienen que ser el centro del proyecto docente, sus inquietudes, su conocimiento inicial, lo que los hace especiales (sus virtudes), su humanidad. A partir de ahora todo esto va a estar muy presente en mi práctica docente, el lado humano y el trato de igual a igual, todo esto serán componentes claves a la hora de preparar y desarrollar mi práctica docente junto con el resto de principios didácticos que se describen en el siguiente apartado.

\section{Principios Didácticos}

Los alumnos aprenden cuando tienen interés (se divierten, disfrutan) por el contenido, sin interés no hay aprendizaje profundo.

1. Los alumnos y los docentes estamos en el mismo barco, todos tenemos que tener el mismo objetivo y remar en la misma dirección, que se respire igualdad y respeto en clase. Las jerarquías entorpecen el proceso de aprendizaje, la humanidad lo facilita.

2. Conocer lo que piensa (planteamientos) el alumno del problema planteado antes de comenzar a trabajar es básico para proporcionar las herramientas adecuadas y no dar palos de ciego.

Ciclos de Mejora en el Aula (2020). Experiencias de Innovación Docente de la US Esta obra se distribuye con la licencia Creative Commons 
3. No interferir en el proceso de construcción de los alumnos hasta que sea necesario (lo comparto, pero a veces me cuesta llevarlo a la práctica, tengo que trabajarlo).

4. Reconocer los distintos tipos de contenidos y darles una estructura coherente en el modelo metodológico completa el aprendizaje y puede ayudar a despertar el interés. Por ejemplo, que no haya solo datos y conceptos sino procedimientos y actitudes puede cambiar totalmente la dinámica de una clase y tener más participación e interés por parte del alumnado.

5. Conocer y entender de forma profunda las preguntas claves y las relaciones secundarias con el resto del temario permite transmitir su importancia y darles contexto. A partir de aquí es importante trabajar bien las actividades que vayan permitiendo contestar estas preguntas de forma progresiva.

6. El modelo metodológico te permite tener coherencia al aplicar el CIMA y organizar las actividades, pero creo que es importante también tener flexibilidad por si hay que hacer cambios sobre la marcha si algo claramente no está funcionando o si hay dificultades (por ejemplo, técnicas) que te obligan a cambiar el guion.

7. Identificar obstáculos en las escaleras es probablemente una de las claves fundamentales que nos permite a los docentes "ayudar" a seguir subiendo escalones, pero se detectan cuando ya ha acabado el CIMA. Imagino que servirán para el siguiente CIMA asumiendo que estos obstáculos van a ser siempre parecidos, pero ya no puedes ayudar a esos alumnos.

8. Fundamental tener claro las diferencias entre evaluación y calificación y usar la evaluación para la auto-mejora como docente.

Ciclos de Mejora en el Aula (2020). Experiencias de Innovación Docente de la US Esta obra se distribuye con la licencia Creative Commons 
Palabras clave: Microbiología I, Grado en Biología, Docencia Universitaria, Experimentación Docencia Universitaria

Keywords: Microbiology I, Degree in Biology, University Teaching, University Teaching Experimentation

\section{Referencias bibliográficas}

Bain, K. (2007). Lo que hacen los mejores profesores universitarios. Valencia: Publicaciones de la Universidad de Valencia.

Finkel, D. (2008). Dar clase con la boca cerrada. Valencia, España: Universitat de Valencia.

García-Díaz, E., Porlán, R. y Navarro, E. (2017). Los fines y los contenidos de enseñanza. En R. Porlán (Coord.), Enseñanza Universitaria. Cómo mejorarla. (pp. 55-72). Madrid: Morata.

Rivero, A. y Porlán, R. (2017). La evaluación en la enseñanza universitaria. En R. Porlán (Coord.), Enseñanza Universitaria. Cómo mejorarla, (pp. 74-91). Madrid: Morata.

Ciclos de Mejora en el Aula (2020). Experiencias de Innovación Docente de la US Esta obra se distribuye con la licencia Creative Commons 